\title{
The influence of the atmospheric boundary layer on nocturnal layers of noctuids and other moths migrating over southern Britain
}

Article

Accepted Version

The original publication is available at www.springerlink.com

Wood, C. R., Chapman, J. W., Reynolds, D. R., Barlow, J. F., Smith, A. D. and Woiwod, I. P. (2006) The influence of the atmospheric boundary layer on nocturnal layers of noctuids and other moths migrating over southern Britain. International Journal of Biometeorology, 50 (4). p. 193. ISSN 1432-1254 doi: https://doi.org/10.1007/s00484-005-0014-7 Available at https://centaur.reading.ac.uk/1629/

It is advisable to refer to the publisher's version if you intend to cite from the work. See Guidance on citing.

Published version at: http://dx.doi.org/10.1007/s00484-005-0014-7

To link to this article DOI: http://dx.doi.org/10.1007/s00484-005-0014-7

Publisher: Springer

Publisher statement: The original publication is available at www.springerlink.com

All outputs in CentAUR are protected by Intellectual Property Rights law, including copyright law. Copyright and IPR is retained by the creators or other copyright holders. Terms and conditions for use of this material are defined in the End User Agreement. 


\section{www.reading.ac.uk/centaur}

\section{CentAUR}

Central Archive at the University of Reading

Reading's research outputs online 


\title{
The influence of the atmospheric boundary layer on nocturnal layers of noctuids and other moths migrating over southern Britain
}

\author{
Curtis R Wood ${ }^{1,2 *}$, Jason W Chapman ${ }^{2}$, Donald R Reynolds ${ }^{3}$, Janet F Barlow ${ }^{1}$, Alan D \\ Smith $^{2}$ and Ian P Woiwod ${ }^{2}$
}

\footnotetext{
${ }^{1}$ Department of Meteorology, University of Reading, Earley Gate, Reading, Berkshire, RG6 6BB, UK

${ }^{2}$ Rothamsted Radar Entomology Unit, Plant and Invertebrate Ecology Division, Rothamsted Research, Harpenden, Hertfordshire, AL5 2JQ, UK
}

${ }^{3}$ Natural Resources Institute, University of Greenwich, Central Avenue, Chatham, Kent ME4 4TB, UK

\footnotetext{
* Corresponding author

E-mail: c.r.wood@ reading.ac.uk
}

Tel: +44(0)118378 8954

Fax: $+44(0) 1183788905$ 
Abstract. Insects migrating at high altitude over southern Britain have been continuously monitored by automatically-operating, vertical-looking radars over a period of several years. During some occasions in the summer months, the migrants were observed to form welldefined layer concentrations, typically at heights of $200-400 \mathrm{~m}$, in the stable night-time atmosphere. Under these conditions, insects are likely to have control over their vertical movements and are selecting flight heights which are favourable for long-range migration. We therefore investigated the factors influencing the formation of these insect layers by comparing radar measurements of the vertical distribution of insect density with meteorological profiles generated by the UK Met. Office's Unified Model (UM). Radar-derived measurements of mass and displacement speed, along with data from Rothamsted Insect Survey light traps provided information on the identity of the migrants. We present here three case studies where noctuid and pyralid moths contributed substantially to the observed layers. The major meteorological factors influencing the layer concentrations appeared to be: (a) the altitude of the warmest air, (b) heights corresponding to temperature preferences or thresholds for sustained migration and (c), on nights when air temperatures are relatively high, wind-speed maxima associated with the nocturnal jet. Back-trajectories indicated that layer duration may have been determined by the distance to the coast. Overall, the unique combination of meteorological data from the UM and insect data from entomological radar described here show considerable promise for systematic studies of high-altitude insect layering.

\section{Keywords}

Insect layering - nocturnal boundary layer - temperature inversion - noctuid moths entomological radar 


\section{Introduction}

Many insect species have a migratory phase in their life-cycle, and migrations often begin when individuals ascend out of their 'flight boundary layer' (FBL'1: Taylor 1974), and climb to altitudes of several hundred metres above the ground. Here insects can utilize the typically stronger winds to travel much further during a night's flight than would have been feasible at ground level (Johnson 1969; Drake and Gatehouse 1995; Pedgley et al. 1995; Gatehouse 1997). This behaviour leads to an enormous insect 'bioflow' through the atmosphere, particularly in the warmer regions of the world, and during summer at higher latitudes. Apart from its intrinsic interest, the atmospheric transport of insects is worthy of study because many migrant species are serious pests of agriculture and human health (Pedgley 1982, 1993; Irwin and Thresh 1988; Drake and Gatehouse 1995), while other insects are beneficial because they are important natural enemies of pest species (Farrow 1981; Riley et al. 1987; Chapman et al 2004). In both cases, knowledge of insect movement is necessary when formulating or improving management strategies for the species concerned.

The development and use of radar in insect migration studies has made it possible to make direct quantitative observations of the high-altitude movements whilst they are in progress, particularly for larger insect species such as Lepidoptera (e.g. Dickison et al. 1983; Riley et al. 1983; Drake and Farrow 1985; Chen et al. 1989; Wolf et al. 1990; Feng et al. 2003, 2004). These species have appreciable self-powered flight speeds and, if they cease wingflapping, significant fall speeds: thus larger migrants cannot be regarded as completely passive tracers of the wind. Yet radar observations show that insects can be influenced by atmospheric processes, for example, gravity currents (Schaefer 1976; Greenbank et al. 1980; Pedgley et al.

\footnotetext{
${ }^{1}$ FBL: The layer of air next to the ground where wind speed is lower than an insect's flight speed and hence where an insect has control over its velocity.
} 
1982), atmospheric waves (Drake 1985) and cellular convection (Schaefer 1976; Reid et al. 1979). One commonly observed phenomenon is the accumulation of insects into layers of broad horizontal, but of relatively restricted ( 50-200 m) vertical extent (Drake 1984; Drake and Farrow 1988; Drake and Rochester 1994). The layering phenomenon has been observed at various times of the day and night, at altitudes ranging from a few metres above the ground (as in the visual observations of Mel'nichenko (1936) and Larsen (1949) of moths flying in an early evening temperature inversion) up to $\sim 2-3 \mathrm{~km}$ during the day (Campistron 1975; Drake and Farrow 1985). Sometimes several (up to five) layers are present simultaneously, one above the other (Drake and Farrow 1988). Despite the frequent observations of layers, the behavioural mechanisms causing them are by no means clear and more case studies are required.

Many high-altitude insect migrations begin around dusk and these continue for varying periods through the night (and sometimes all night: Drake et al. 1981; Feng et al. 2004). Nocturnal migrations have presumably evolved because the risk of bird predation is diminished (Drake and Farrow 1988) and thermal stress can be prevented (Rainey 1974). Moths, particularly the Noctuidae (which include important agricultural pests), are likely to be important constituents of the radar-detectable nocturnal fauna, particularly in temperate environments (Drake et al. 1981; Chen et al. 1989; Feng et al. 2003, 2004). Moreover, the dynamics and vertical structure of the nocturnal atmospheric boundary layer (NBL) itself are often optimal for long-range migrations in certain insect species - particularly in the stably stratified state found in flat inland areas during fine weather. In particular, radiative cooling from the earth's surface is much more rapid than cooling of the air itself, hence temperature inversions grow from the ground upwards near dusk (Mahrt 1979); many reports indicate that insects are associated with these surface radiative inversions. The resulting static stability increase causes a decoupling of flow above and below the inversion; above the inversion height 
flow can accelerate into a nocturnal jet (Thorpe and Guymer 1977). There is evidence that migrants use these low-level jets to achieve rapid horizontal transport (Drake 1985; Drake and Farrow 1988).

Until recently, most observations of nocturnal layering have been made with azimuthally-scanning X-band radars, but because these systems are typically manually operated, field studies have generally been of short duration ( 1-2 weeks). Entomological scanning radars are now tending to be replaced by autonomously-operating vertically-pointing systems; these can provide continuously updated profiles of insect vertical distribution over whole seasons, or even years (Smith et al. 2000; Drake 2002; Chapman et al. 2003).

The key objective of this paper is to present case studies where meteorology apparently has an effect on nocturnal insect layering in the UK and, by extension, in northern Europe - an area virtually unstudied by entomological radar techniques and previously suspected to be climatically marginal for night-time migrations. Additionally, this paper highlights that the new insect-monitoring radars, combined with outputs from the constantly-developing suites of computer models used in numerical weather prediction (in this case the UK Met. Office's Unified Model), hold out the prospect of employing these tools in systematic studies of insect layers in the atmosphere (Drake and Rochester 1994).

\section{Materials and methods}

Radar-derived insect data

Entomological radar is the only effective method of directly observing migrating insects at high altitude (see reviews in Vaughn 1985; Drake and Farrow 1988; Reynolds and Riley 1997; Smith et al. 2000; also The Radar Entomology Website: ihttp://www.ph.adfa.edu.au/a- 
drake/trews/). In this study, we used the recently-developed vertical-looking insect-monitoring radar (VLR) technique (Chapman et al. 2002b, 2003; Drake 2002) which, at least for macroinsects, gives instantaneous vertical profiles of insect aerial density over virtually all migration altitudes to be expected over the UK.

The radar used in the present study was located at Malvern, Worcestershire - during the August 2000 case study at lat. $52^{\circ} 7^{\prime} 54^{\prime \prime} \mathrm{N}$, long. $2^{\circ} 19^{\prime} 55^{\prime \prime} \mathrm{W}(86 \mathrm{~m}$ asl) and during the August 2003 studies at a nearby site $52^{\circ} 06^{\prime} 04^{\prime \prime} \mathrm{N}, 2^{\circ} 18^{\prime} 38^{\prime \prime} \mathrm{W}(59 \mathrm{~m}$ asl). The $3.2 \mathrm{~cm}$ wavelength (X-band) radar beam is circularly-symmetric and zenith-pointing, and the plane of linear polarisation is continuously rotated at about $5.8 \mathrm{~Hz}$. In addition, the beam nutates due to a slight offset ( 0.1 beam widths) in the antenna feed, producing a narrow-angle conical scan. The $1.5 \mathrm{~m}$ diameter parabolic antenna gives a half-power beam width of $1.4^{\circ}$. The pulse duration is 100 nano-seconds, and the peak pulse power is $25 \mathrm{~kW}$. Data are recorded during a 5-minute sampling period, repeated every 15 minutes, 24 hours a day. Return signals from individual insect targets flying through the radar beam are detected in fifteen range-gates (sampling volumes), each $45 \mathrm{~m}$ deep with $26 \mathrm{~m}$ non-sampled intervals to give coverage from 180-1218 m. The system routinely extracts the target's distance of closest approach to the beam's central axis, horizontal speed, displacement direction, body alignment, and three terms that describe the radar scattering properties of the target. Using laboratory measurements of radar cross-sections of insects, the back scattering terms can be routinely employed to estimate the target's mass and shape (Chapman et al. 2002b). All the radar-derived variables can then be used to infer the target's identity, and these inferences were further supported by ground trap data or, occasionally, by aerial sampling. The analysis program also routinely records the percentage of time the received signal power is above certain power (threshold) levels, particularly the $-80 \mathrm{dBm}\left(10^{-11}\right.$ Watts $)$ level which is $\sim 10 \mathrm{~dB}$ over the noise floor of the radar receiver. These 'percentage above threshold' values provide a measure of the biomass of 
insects flying: useful in situations where aerial-densities are too high for individual targets to be resolved by the radar. Further details of the radar system, its mode of operation and analysis protocols, including target identification procedures to deal with non-insect targets (such as precipitation, 'chaff', birds and bats) have been described elsewhere (Smith et al. 1993; Smith et al. 2000; Chapman et al. 2002b, 2003; Reynolds et al. 2005).

The radar database was scanned for evidence of layering using a 'Visual Basic' module which returned a "Layer Quality" code (a number from 0-7) indicating the layering status of each vertical profile (Reynolds et al. 2005), taking into account the numbers of all resolvable targets and the 'percentage above threshold values' (see above). If strong layers occurred in a succession of profiles (at 15-minute intervals) over a period of 2-3 hours during an evening, the relevant profiles were examined in more detail on a case study basis. Insect aerial densities (expressed here as the number of insects per $10^{7} \mathrm{~m}^{3}$ ) were calculated for targets which were well described by the underlying analysis model (Chapman et al. 2002b), and where estimated masses and other radar-derived variables were expected to be reliable.

Insect data from ground traps

Although the radars can provide information on several variables, which are useful for the identification of radar targets, it is rational to place this information in the context of the relative abundance and temporal occurrence of named species of insect. As we were particularly interested in moths, use of data from the Rothamsted Insect Survey's (RIS) UKwide network of light traps (Woiwod and Harrington 1994) complemented the radar-derived variables.

Meteorological data 
The UK Met. Office's (UKMO) operational numerical weather prediction model - the Unified Model (UM) - is the source of meteorological data used here. The model assimilates real weather data, along with interpolative tools and physical equations, to provide meteorological output at various locations (grid-boxes) throughout the country. The UM (version 5 onwards) solves non-hydrostatic, deep-atmosphere dynamics using a semi-implicit, semi-Lagrangian numerical scheme (Cullen et al. 1997). The model includes a comprehensive set of parameterizations, including surface (Essery et al. 2001), boundary layer (Lock et al. 2000), mixed phase cloud microphysics (Wilson and Ballard 1999) and convection (Gregory and Rowntree 1990), with additional downdraft and momentum transport parameterizations. The model runs on a rotated latitude/longitude horizontal grid with Arwakawa $\mathrm{C}$ staggering and a terrain-following hybrid-height vertical coordinate with Charney-Philips staggering. Operationally the UKMO run a 'mesoscale' domain with horizontal resolution of 0.11 degrees (approximately $12.5 \mathrm{~km}$ ). The model runs with 38 levels spaced non-uniformly in the vertical range. Data are extracted every hour for the present study to provide vertical and temporal profiles of meteorological variables at the grid-box corresponding to the Malvern radar. Several meteorological variables were extracted: most relevant are wind speed, air temperature and relative humidity $(\mathrm{RH})$.

Utilising these data is an improvement over the use of network radiosonde launches alone. Operational radiosonde ascents are available once per night and at locations not particularly close to the radar site (the most relevant upper-air stations currently in use are Camborne, Nottingham, Larkhill and Herstmonceux). Account was nevertheless taken of the radiosonde data in order to check the UM-derived profiles.

In order to estimate the take-off location of radar observed insects, back-trajectories were produced using the NAME trajectory model (hittp://www.met-1 
office.gov.uk/research/nwp/publications/nwp_gazette/dec00/name.html) which uses UM analyses of wind evolution in space and time. This method does not take into account any local turbulence effects on insect flight and does not simulate self-powered insect flight speed. It does, however, assume that the insects maintain a constant height of $300 \mathrm{~m}$ above the ground.

All timings referred to in this work are in Coordinated Universal Time (UTC), which is one hour earlier than British Summer Time (BST).

\section{Results}

Three case studies of nocturnal layering events were selected from a substantial data-set (2000 onwards). Cases were chosen on the basis of the presence of well-defined and persistent insect layers, apparently consisting of rather similar species, which occurred during stable atmospheric conditions - specifically high atmospheric pressure with largely clear skies (which promote temperature inversions and nocturnal jets). It is worth noting that such meteorological conditions occur typically on 10-15 nights per summer month in southern Britain.

Case study A: 22-23 August 2000

The evolution of the vertical profile of insect aerial density throughout the evening and night of 22-23 August at Malvern (Fig. 1) shows a dusk take-off underway by about 19:30 with aerialdensities up to 100 insects per $10^{7} \mathrm{~m}^{3}$. At 19:45 the decrease in the insect aerial density with height was semi-logarithmic (c.f. Drake 1984), up to approximately $650 \mathrm{~m}$. A distinct layer in the vertical profile of insects had formed by 21:00 at about $400 \mathrm{~m}$ above ground level (agl). 
The layer centre decreased in altitude by about $70 \mathrm{~m}$ from 23:00 to 01:00, after which the layer dissipated, and aerial densities then remained low for the rest of the night. Maximum densities recorded within the layer were $\sim 100$ insects per $10^{7} \mathrm{~m}^{3}$, and layer depth (defined by the 25 insects per $10^{7} \mathrm{~m}^{3}$ contour) varied between 250 and $400 \mathrm{~m}$.

It is highly likely that the insects forming the layer took off at dusk and that no further significant take-off of insects occurred later in the night. Therefore, the insects observed at Malvern at 01:00 had probably been flying for about 5 hours. Back-trajectory analysis revealed that a parcel of air at $300 \mathrm{~m}$ present over Malvern at 01:00 would have been located around 150 $\mathrm{km}$ to the east at 20:00 (Fig. 2, trajectory A). There is, however, good evidence of approximately downwind orientation by the insects forming the layer (see below), so an additional component of $\sim 4 \mathrm{~m} \mathrm{~s}^{-1}$, representing the self-powered flight speed of the migrants, can be added to the wind speed. Thus the insects may have travelled a further $70 \mathrm{~km}$ between 20:00 and 01:00, giving a total estimated migration distance of around $220 \mathrm{~km}$. This almost corresponds to the distance to the East Anglian coast, and the lack of further sources beyond this point may explain the sudden decline in insect numbers at 01:00. The maintenance of high insect numbers before 01:00 also suggests widespread source locations of the insect species concerned.

The meteorological data generated from the UM at Malvern showed that a surface temperature inversion was present from 21:00 to 04:00 on 22-23 August (Fig. 3). The top of the inversion (i.e. height of maximum temperature, depicted by the magenta line) was located near $300 \mathrm{~m}$ agl and showed a slight tendency to rise in altitude until 01:00. The temperature maximum decreased from 16 to $14^{\circ} \mathrm{C}$ between 21:00 and 01:00. For much of the night the centre of the insect layer was located $\sim 50 \mathrm{~m}$ above the maximum temperature, implying that most insects were experiencing temperatures of at least $14^{\circ} \mathrm{C}$. Furthermore, the upper boundary of the insect layer, located at around $500-550 \mathrm{~m}$, coincided approximately with the $14^{\circ} \mathrm{C}$ 
isotherm throughout (see dashed line denoting the 25 insects per $10^{7} \mathrm{~m}^{3}$ contour in Fig. 3). This may imply that the layer is a 'ceiling layer' with a threshold of minimum temperature for flight near $14^{\circ} \mathrm{C}$. However, as the threshold for sustained flight in at least some British noctuids is lower than $14^{\circ} \mathrm{C}$ (e.g. $10.5^{\circ} \mathrm{C}$ in the mouse moth, Amphipyra tragopoginis: Taylor and Carter 1961), the observed upper extent of the layer may be indicative of a preferred temperature rather than an absolute threshold.

Both RH and wind shear featured high gradients near the altitude of $200 \mathrm{~m}$ throughout the migration period (not shown). These gradients are associated with the NBL top (e.g. Garratt 1994) which indicates that migration was occurring in the residual layer above, where turbulence is minimal. Further study revealed that the insect layer was located in a layer of less humid air $(<65 \% \mathrm{RH})$, with higher values (up to $80 \% \mathrm{RH})$ above and below the layer.

UM data showed that a nocturnal jet formed from 20:00 to 00:00 (Fig. 4). The wind speed maximum occurred at about $300 \mathrm{~m}$, and was most intense $\left(14 \mathrm{~m} \mathrm{~s}^{-1}\right)$ between 21:00 and 22:00. Radio-soundings at Herstmonceux, East Sussex (00:00) and Larkhill, Wiltshire (06:00) also provided evidence for a jet, again with the strongest wind speeds $\left(14 \mathrm{~m} \mathrm{~s}^{-1}\right)$ at about 300 $\mathrm{m}$. The centre of the insect layer observed at Malvern apparently remained no more than $50 \mathrm{~m}$ above the jet centre (Fig. 4) and hence typical wind speeds experienced by insects were 12-13 $\mathrm{m} \mathrm{s}^{-1}$.

The displacement speeds (net speed relative to the ground) of insects flying in the layer and recorded by the radar are shown in Fig. 5. The highest displacement speeds $\left(18-20 \mathrm{~m} \mathrm{~s}^{-1}\right)$ occurred between $21: 00$ and 22:00, i.e. they corresponded approximately to the maximum speeds in the nocturnal wind jet. Scalar subtraction of UM wind speeds from the radar-derived insect displacement speeds gave an estimate of the insect flight speed. The majority of insects had estimated flight speeds of approximately $4 \mathrm{~m} \mathrm{~s}^{-1}$, and this seems reasonable for the noctuid moths (Lewis and Taylor 1967; Lingren et al. 1995) contributing to the layer (see below). 
Radar measurements of body alignment for insects in the layer showed evidence of the common orientation phenomenon (Reynolds and Riley 1986; Riley 1989) (see Fig. 6). There is a $180^{\circ}$ ambiguity in the actual insect headings, but consideration of the insects' displacement vectors and flight speed make it clear that the mean orientation was towards the WSW (the mean orientation angle was $244.6^{\circ}$ with a circular standard deviation (CSD) of $30.5^{\circ}, 1062$ targets). The mean displacement direction was towards $262.7^{\circ}\left(\mathrm{CSD}=25.5^{\circ}\right)$ so the insects were evidently orientating at an angle slightly anti-clockwise from the downwind direction.

The radar-estimated masses of insects in the layer provide an aid to identification (Fig. 7). The insect mass distribution remained almost unchanged throughout the duration of the layer: various sizes of insect were present, but a large peak (comprising 35\% of the insects) occurred in the 80-160 mg group. Medium-sized noctuid moths are the most likely component of the nocturnally migrant insect fauna in this size range. Examination of the catch from the nearest RIS light trap to the Malvern radar (Bredon Hill, Worcestershire; $20 \mathrm{~km}$ east of the radar) showed that the most common species of noctuid moths caught on this night were: Xestia c-nigrum (setaceous hebrew character) Diarsia rubi (small square-spot), Mythimna pallens (common wainscot), Ochropleura plecta (flame shoulder), Luperina testacea (flounced rustic) and Autographa gamma (silver Y). There is some evidence for windborne migration in X. c-nigrum and M. pallens (Reynolds et al. 2005). A. gamma is a well-known migrant (Taylor et al. 1973) and indeed it has been caught by us in high-altitude aerial samples (see below): its mass $(146 \mathrm{mg} ; \mathrm{n}=11)$ places it within the $80-160 \mathrm{mg}$ peak observed for the insects forming the layer.

Case study B: 14-15 August 2003 
The evolution of the vertical profile of insect aerial density throughout the evening and night of 14-15 August 2003 at Malvern is shown as black contour lines on Fig. 8 - which also shows changes in the temperature profile. Dusk take-off lasted until 20:45, and a distinct layer had formed by $21: 30$ at about $200-450 \mathrm{~m}$ agl. The layer rose in altitude until 23:30 when it was located at 300-500 m, and then it decreased with altitude until 01:45, after which time the layer dissipated. Maximum densities of $\sim 100$ insects per $10^{7} \mathrm{~m}^{3}$ were recorded in the dusk emigration peak, but densities were always lower than 65 insects per $10^{7} \mathrm{~m}^{3}$ within the layer. Density values were thus less than in the layer described in case study A above. Layer depth defined by the 25 insects per $10^{7} \mathrm{~m}^{3}$ contour - varied from $<70 \mathrm{~m}$ up to $200 \mathrm{~m}$. The duration of migration is likely to have been about five hours (20:30 and 01:30). Back-trajectory analysis showed that a parcel of air moving at a height of $300 \mathrm{~m}$ and arriving at Malvern at 01:30, would have originated at around $130 \mathrm{~km}$ north of the radar site at 20:30 (Fig. 2, trajectory B). The back-trajectory has a curved shape due to a high pressure system centred west of the UK. The insects forming the layer again showed a tendency to orientate downwind - the mean orientation angle was $207.5^{\circ}\left(\mathrm{CSD}=29.5^{\circ}, 642\right.$ targets $)$ and the mean displacement direction was towards $205.5^{\circ}\left(\mathrm{CSD}=26.9^{\circ}\right)$. Therefore, taking into consideration a component of $4 \mathrm{~m}$ $\mathrm{s}^{-1}$ for the insect flight speed (see case study A), an extra $70 \mathrm{~km}$ of flight distance may have been covered on this night, giving a total estimated migration distance of around $200 \mathrm{~km}$. The fact that the source area of insect take-off is estimated to be near the coast is again a possible reason for the layer dissipation seen at Malvern after 01:45.

The evolution of the temperature profile on the night of 14-15 August is shown in Fig. 8. Before about 23:00, the warmest temperatures occur quite close to the surface (within the first $100 \mathrm{~m}$ ), and sonde ascents also indicated that the top of the inversion was located at relatively low altitude on this night (e.g. $175 \mathrm{~m}$ at Nottingham at midnight). Therefore it seems clear that, in this case, the insects were not concentrated at the height of the warmest air. The 
temperature profile suggests that up until $23: 30$ most insects flew in air of $14-16^{\circ} \mathrm{C}$, with the upper layer boundary located in the $12-14^{\circ} \mathrm{C}$ region, suggesting a minimum temperature preference or threshold for flight near $12^{\circ} \mathrm{C}$. The majority of insects flew in air of less than 75\% $\mathrm{RH}$ and there was a general increase of $\mathrm{RH}$ with time at all altitudes (not shown). Fig. 9 shows that wind speeds of up to $10 \mathrm{~m} \mathrm{~s}^{-1}$ were present in a nocturnal jet from 21:00 to 23:00 at 200-300 m, but insects still flying after 01:00 may have experienced winds as low as $5 \mathrm{~m} \mathrm{~s}^{-1}$. The insect layer appeared to be centred slightly above the wind jet in a region of negative wind shear (i.e. wind speed decreased with altitude). This is similar to the observations in case study A.

The insect mass distribution again showed a peak in the 80-160 mg group (Fig. 7), and medium-sized noctuid moths are the most likely component of the nocturnally migrant insect fauna in this size range. Examination of the RIS catch from Bredon Hill showed that the most common species of noctuid moth caught on this night were: X. c-nigrum, M. pallens, O. plecta and Thalpophila matura (straw underwing). The highly migratory species, A. gamma (silver Y), was caught in the light-trap in the days before and after this layering event. Further evidence for mass migration of this species was the capture of specimens in a balloonsupported net at $200 \mathrm{~m}$ above Cardington airfield, Bedfordshire $\left(52^{\circ} 06^{\prime} \mathrm{N}, 0^{\circ} 25^{\prime} \mathrm{W}\right)$ on the evenings of 19, 20 and 24 August 2003 (JW Chapman and DR Reynolds, unpublished). Although the noctuids may have constituted a large portion of the radar-detected insects, three migratory micro-moth species were also found in trap catches, namely: Plutella xylostella (diamondback moth) (Yponomeutidae), Nomophila noctuella (rush veneer) and Udea ferrugalis (rusty dot pearl) (both Pyralidae). Plutella xylostella is too small (1-4 mg) to have been easily detectable in the layer (Chapman et al. 2002a), but $N$. noctuella (16-25 mg) and $U$. ferrugalis $(\sim 10 \mathrm{mg})$ could have been among the smaller insects detected by the radar in the 10 $40 \mathrm{mg}$ size groups (Fig. 7). Altogether, these findings imply that good numbers of moths were 
migrating, and indeed migrations in mid to late August are likely to involve southward return movements to over-wintering sites in several species. Certainly, the northerly winds recorded on this night would have aided such a migration strategy.

Case study C: 23-24 August 2003

The evolution of the vertical profile of insect aerial density throughout the evening and night of 23-24 August at Malvern is shown as black contour lines on Fig. 10 - in addition to the evolution of the temperature profile. Dusk take-off was seen to be ending by 20:00 judging by the reduced densities in the lowest range-gate. A distinct layer had formed by $20: 30$, in the region 200-600 $\mathrm{m}$ above ground. The lower edge of the layer was only just visible on the radar, but its centre apparently showed little tendency to change in altitude and its depth was never less than $300 \mathrm{~m}$. The layer dissipated at 00:45, and aerial densities then remained low for the rest of the night. Maximum densities of $\sim 90$ insects per $10^{7} \mathrm{~m}^{3}$ were recorded near 20:30, and densities above 50 insects per $10^{7} \mathrm{~m}^{3}$ occurred within the layer for much of its duration. Migration duration appeared to be about 5 hours, based on a take-off just before 20:00 and layer dissipation just before 01:00. Back-trajectory analysis (Fig. 2, trajectory C) reveals that a parcel of air at $300 \mathrm{~m}$ over Malvern at 01:00 would have originated at around $80 \mathrm{~km}$ to the north at 20:00. The mean orientation angle of insects forming the layer was $208.7^{\circ}$ (CSD $=$ $39.8^{\circ}, 1461$ targets $)$ and their mean displacement direction was towards $210.3^{\circ}\left(\mathrm{CSD}=28.7^{\circ}\right)$. Thus an extra $70 \mathrm{~km}$ can be added to take account of the insect flight speed (see case study A), and this suggests an estimated migration distance of around $150 \mathrm{~km}$. Hence, the proposition that insects observed near the end of the layering event (01:00) took off near the coast cannot be discounted, particularly given the curvature of the horizontal wind field shown on backtrajectory $\mathrm{C}$. 
The evolution of the temperature profile (Fig. 10) shows that temperatures were distinctly warmer than in case studies A and B. Most insects flew above the height of the temperature maximum, in air of $18-21^{\circ} \mathrm{C}$ throughout the night. The upper layer boundary was located in the $17-18^{\circ} \mathrm{C}$ region; this is likely to be higher than the minimum temperature threshold for flight, given the likely species constituting the layer. This implies that temperature was not limiting insect flight altitude, as was suggested in cases A and B. It is possible that in this case maximum wind speed was the significant variable determining layer altitude. Fig. 11 shows that a nocturnal jet was present, with maximum speeds of $8 \mathrm{~m} \mathrm{~s}^{-1}$ between 21:00 and 00:00 at height 200-300 m. The jet centre was located at the same altitude as the centre of the insect layer and most insects would have experienced wind speeds above 6 $\mathrm{m} \mathrm{s}^{-1}$.

The insect mass distribution again showed a peak in the 80-160 mg group (Fig. 7). The nearest working RIS light-trap was at Hereford (30 km west of the radar), and noctuids caught included X. c-nigrum, M. pallens and the rare UK migrant Spodoptera exigua (small mottled willow or beet armyworm). The northerly wind experienced in this migration event is consistent with southward return migrations to over-wintering sites. Catches of S. exigua in the RIS light-traps first appeared in June, probably indicating an early northward invasion of the species and subsequent return southwards (c.f. Johnson 1969, p. 516).

\section{Discussion}

Large insects flying in the stable atmospheric boundary layer at night would be expected to have more control over their altitude of migration than, say, small insects flying under convective conditions during the day (Gatehouse 1997). We envisage the migrant moths (which form the subject of the present study) climbing steeply after take-off in order to rise 
above their FBL (Johnson 1969 p. 81; Lingren et al. 1995), and then ascending more gradually (at $\sim 0.5 \mathrm{~m} \mathrm{~s}^{-1}$; Riley et al. 1983) until they reach altitudes of several hundred metres where conditions seem optimal for migratory flight. The migrants will then tend to accumulate at these altitudes, and if the resulting concentrations are relatively restricted in depth, they will be perceived on the radar as layers. Apart from the effects of atmospheric conditions on flight altitude (see below), there are presumably other limits on the vertical distance a large insect will climb before it levels out - these may be controlled by internal physiological restraints such as energy expended in climbing flight, or conceivably by optomotor reactions to ground patterns (of which little is known for high-flying insects: Riley 1989). After reaching their 'cruising' altitude, nocturnal migrants will maintain steady and continuous flight, often for a period of several hours, during which time they will be displaced considerable horizontal distances in an approximately downwind direction. In southern Britain, migrations are usually over by about midnight or 01:00 (present study; Reynolds et al. 2005). Flights of moths continuing through the whole night until dawn or beyond (which have been observed in other regions of the world; Drake et al. 1981; Drake 1985; Wolf et al. 1990; Beerwinkle et al. 1994; Feng et al. 2004) are apparently uncommon in the UK (Reynolds et al. unpublished data). Since Britain is an island, some of the more abrupt flight terminations may be due to a lack of source areas beyond the coasts - indeed this may have occurred in the current study - rather than because air temperatures have dropped below thresholds for sustained flight or because flight fuel reserves have been exhausted.

A key question is thus: which environmental factors present in, for example, the first kilometre of the nocturnal atmosphere will have most influence on the migration altitude of large insects? Temperature would be expected to be a primary influence, as this variable affects many other aspects of insect physiology and behaviour, and there are plenty of studies to support this view (Drake and Farrow 1988; Gatehouse 1997). The simplest case is where the 
insects have selected the altitude of the warmest air, often at the top of a surface temperature inversion (Schaefer 1976; Drake 1984; Drake and Farrow 1988; Feng et al. 2003; Reynolds et al. 2005) or occasionally a higher-altitude temperature maximum, such as that due to a subsidence inversion (Reynolds et al. 2005). Selection of the warmest air by migrants appears to be most likely to occur in relatively cool conditions, and in taxa that have high optimum temperatures for migratory flight. For example, migratory acridoid insects (grasshoppers and locusts) have optimum temperature values for sustained flight of above $20^{\circ} \mathrm{C}$ (Clark 1969 ; Riley and Reynolds 1979), which are much higher than for instance the noctuid moths studied here (see also Taylor and Carter, 1961). On the other hand, there are many references in the literature in which insects, particularly moths, have ascended above the altitude of the temperature maximum. On some of these occasions insects may be forming 'ceiling layers', i.e., ascent has continued until insects reach an altitude corresponding to the lowest temperature at which they can sustain flight. A good example is the sharp upper boundary of layers of the brown planthopper, Nilaparvata lugens in China (Riley et al. 1991): these layers were well above the altitude of the temperature maximum, but the layer tops corresponded to known temperature thresholds $\left(\mathrm{ca} .16{ }^{\circ} \mathrm{C}\right)$ for sustained flight in the planthoppers. Ceiling layers may also be implicated in cases of high-altitude layering where there is no obvious corresponding feature in the vertical profile of meteorological variables (Drake and Farrow (1985) observed one as high as $1900 \mathrm{~m}$ agl in eastern Australia), and in cases where maximum flight altitudes of certain taxa (grasshoppers, say) show a general decrease in line with seasonal air temperatures (Schafer 1976; Reynolds and Riley 1997).

The present observations in southern UK were made in a cooler climate than most previous radar entomology studies, and it was to be expected that even noctuid moth migration would be strongly restrained by temperatures on many occasions. A good indication that temperatures were sub-optimal on many nights was the observation that when migratory 
activity occurred at dusk, it frequently did not persist for long after dark (Wood, Reynolds et al. unpublished data). When night-time layering did develop, moths have been observed to fly at the altitude of the warmest air (Reynolds et al. 2005), but sometimes it may be difficult to distinguish (as in our case study A above) between this effect of temperature and the formation of a 'ceiling' layer. However, in our case study B, the observed insect layer was well above the height of the temperature maximum, and was most easily explained by a restriction on migratory flight due to the cooler air at higher altitudes.

Notwithstanding the above findings, there are many reports in the literature where the insect layers are closely associated with wind-related variables (i.e. wind velocity, shear zones, turbulence) and conspicuously unrelated to air temperature profiles (Wolf et al. 1986; Hobbs and Wolf 1989; Beerwinkle et al. 1994; Feng et al. 2004). A necessary condition in these cases is presumably that night-time air temperatures are significantly above flight thresholds for the taxa concerned, freeing the insects of the need to migrate at the warmest altitudes. Examples where moths contributed to wind-related layers include Helicoverpa zea, Heliothis virescens, Peridroma saucia and other species in the southern USA (Wolf et al. 1986; Beerwinkle et al. 1994), and Loxostege sticticalis and Helicoverpa armigera in north-eastern China (Feng et al. 2004). It seems clear that large insects - such as migratory noctuid moths - are able to detect zones of wind speed maxima, and to fly preferentially within them (Wolf et al. 1986), and this would appear to be an adaptive strategy for maximizing their displacement. Moreover, the migrants are often able either to align themselves in a downwind direction (as in the present study), or to orient at an angle to the wind (but generally one which avoids gross backwards (tail-first) displacement: Riley and Reynolds 1986). The mechanism(s) and adaptive significance of this orientation behaviour are still unclear. In some cases, orientation occurs under severely reduced illumination, which may suggest that insects are able to use non-visual 
cues to detect wind speed and direction, such as anisotropies in turbulence due to KelvinHelmholtz waves (Riley 1989).

Because the boundary-layer wind speed maximum often occurs close to the top of the surface inversions, it can be difficult to distinguish the effects of wind speed from those of temperature. In our case study $\mathrm{C}$, however, an association with the nocturnal jet seemed likely, as the migrants were evidently flying above the level of the warmest temperatures, and 'ceiling layer' effects seemed unlikely because layers of similar species have been observed to migrate at much lower temperatures on previous nights (c.f. case study B).

In summary, the results of the current study indicate that the altitude of layers of migrating moths in the UK may be constrained either by: the altitude of the warmest air (case study A); the altitudes with temperatures which may represent flight thresholds and/or preferenda (case studies A and B); or the altitude of regions of high wind speed when air temperatures are relatively high (case study C).

A case study approach is clearly useful for investigation of migration events involving a preponderance of particular species, as demonstrated by the recent studies of noctuid moths in the UK (the present paper; Reynolds et al. 2005) and elsewhere (Feng et al. 2003; 2004). However, the existence of continuous, high-resolution, co-located meteorological and entomological data-sets available, respectively, from the Unified Model and the verticallooking radar, seem highly suitable for a systematic investigation of the meteorological mechanisms controlling insect layering: we are currently embarking on such a study (CR Wood, in preparation).

\section{Acknowledgements}


We thank Pete Clark from the UK Met. Office's Joint Centre for Mesoscale Meteorology for UM data, Helen Webster from the UK Met. Office's Atmospheric Dispersion Group for backtrajectory analyses and Ann Edwards for obtaining the insect alignment results. This work was supported by the UK Biotechnology and Biological Sciences Research Council (BBSRC) grant BBS/S/L/2003/10273 and a UK Met. Office CASE studentship.

\section{References}

Beerwinkle KR, Lopez JD, Witz JA, Schleider PG, Eyster RS, Lingren PD (1994) Seasonal radar and meteorological observations associated with nocturnal insect flight at altitudes to 900 metres. Env Entomol 23(3):676-683

Campistron B (1975) Characteristic distributions of angel echoes in the lower atmosphere and their meteorological implications. Boundary-Layer Meteorol 9:411-426

Chapman JW, Reynolds DR, Smith AD, Riley JR, Pedgley DE, Woiwod IP (2002a) High-altitude migration of the diamondback moth Plutella xylostella to the U.K.: a study using radar, aerial netting, and ground trapping. Ecol Ent 27:641-650

Chapman JW, Smith AD, Woiwod IP, Reynolds DR, Riley JR (2002b) Development of vertical-looking radar technology for monitoring insect migration. Comp Electron Agric $35: 95-110$

Chapman JW, Reynolds DR, Smith AD (2003) Vertical-looking radar: a new tool for monitoring high-altitude insect migration. Bioscience 53:503-511

Chapman JW, Reynolds DR, Smith AD (2004) Migratory and foraging movements in beneficial insects: a review of radar monitoring and tracking methods. Int J Pest Manag $50: 225-232$ 
Chen RL, Bao XZ, Drake VA, Farrow RA, Wang SY, Sun YJ, Zhai BP (1989) Radar observations of the spring migration into northeastern China of the oriental armyworm moth, Mythimna separata and other insects. Ecol Ent 14:149-162

Clark DP (1969) Night flights of the Australian plague locust, Chortoicetes terminifera Walk., in relation to storms. Aust J Zool 17:329-352

Cullen MJP, Davies T, Mawson MH, James JA, Coulter SC, Malcolm A (1997) An overview of numerical methods for the next generation UK NWP and climate model. In: Lin CA, Laprise R, Ritchie H (eds) Numerical Methods in Atmospheric and Ocean Modelling: The Andre J. Robert memorial volume. Canadian Meteorological and Oceanographic Society, Ottawa, Canada, pp 425-444

Dickison RBB, Haggis MJ, Rainey, RC (1983) Spruce budworm moth flight and storms: case study of a cold front system. J Clim Appl Meteorol 22:278-286

Drake VA (1984) The vertical distribution of macro-insects migrating in the nocturnal boundary layer: a radar study. Bound-Layer Meteorol 28:353-374

Drake VA (1985) Solitary wave disturbances of the nocturnal boundary layer revealed by radar observations of migrating insects. Bound-Layer Meteorol 31:269-286

Drake VA (2002) Automatically operating radar for monitoring insect pest migrations. Entomol Sinica 9(4):27-39

Drake VA, Farrow RA (1985) A radar and aerial-trapping study of an early spring migration of moths (Lepidoptera) in inland New South Wales. Aust J Ecol 10:223-235

Drake VA, Farrow RA (1988) The influence of atmospheric structure and motions on insect migration. Ann Rev Ent 33:183-210

Drake VA, Gatehouse AG (1995) (eds) Insect Migration: Tracking Resources through Space and Time. Cambridge University Press, Cambridge, UK 
Drake VA, Helm KF, Readshaw JL, Reid DG (1981) Insect migration across Bass Strait during spring: a radar study. Bull Ent Res 71:449-466

Drake VA, Rochester WA (1994) The formation of layer concentrations by migrating insects. In: Proceedings of 21st Conference on Agricultural and Forest Meteorology - 11th Conference on Biometeorology, March 7-11 1994, San Diego, California. American Meteorological Society, Boston, pp. 411-414

Essery R, Best M, Cox P (2001) MOSES 2.2 Technical Documentation, Hadley Centre Technical Report No. 30, UK Met. Office Hadley Centre

Farrow RA (1981) Aerial dispersal of Scelio fulgidus (Hym.: Scelionidae), parasite of eggs of locusts and grasshoppers (Ort.: Acrididae). Entomophaga 26:349-355

Feng HQ, Wu KM, Cheng DF, Guo YY (2003) Radar observations of the autumn migration of the beet armyworm Spodoptera exigua (lepidoptera: Noctuidae) and other moths in northern china. Bull Ent Res 93:115-124

Feng HQ, Wu KM, Cheng DF, Guo YY (2004) Spring migration and summer dispersal of Loxostege sticticalis (Lepidoptera: Pyralidae) and other insects observed with radar in northern China. Env Entomol 33:1253-1265

Garratt JR (1994) The atmospheric boundary layer. Cambridge atmospheric and space series. Cambridge University Press, Cambridge

Gatehouse AG (1997) Behavior and ecological genetics of wind-borne migration by insects. Ann Rev Ent 42:475-502

Greenbank DO, Schaefer GW, Rainey RC (1980) Spruce budworm (Lepidoptera: Tortricidae) moth flight and dispersal: new understanding from canopy observations, radar, and aircraft. Mem Ent Soc Canada 110:1-49

Gregory D, Rowntree PR (1990) A mass flux convection scheme with representation of cloud ensemble characteristics and stability-dependent closure. Mon Wea Rev 118:1483-1506 
Hobbs SE, Wolf WW (1989) An airborne radar technique for studying insect migration. Bull Ent Res 79:693-704

Irwin ME, Thresh JM (1988) Long range aerial dispersal of cereal aphids as virus vectors in North America. Phil Trans Roy Soc Lond B 321:421-446

Johnson CG (1969) Migration and Dispersal of Insects by Flight. Metheun and Co, London

Larsen EB (1949) Activity and migration of Plusia gamma L. Studies on the activity of insects. III. Biologiske meddelelser 21(4):1-32

Lewis T, Taylor LR (1967) Introduction to Experimental Ecology. Academic Press, London Lingren PD, Raulston JR, Popham TW, Wolf WW, Lingren PS, Esquivel JF (1995) Flight behaviour of corn earworm (Lepidoptera: Noctuidae) moths under low wind speed conditions. Env Entomol 24:851-860

Lock AP, Brown AR, Bush MR, Martin GM, Smith RNB (2000) A new boundary layer mixing scheme. Part 1: Scheme description and single-column model tests. Mon Wea Rev $128: 3187-3199$

Mahrt L, Heald RC, Lenschow DH, Stankov, BB, Troen I (1979) An observational study of the structure of the nocturnal boundary layer. Bound-Layer Meteorol 17:247-264

Mel'nichenko AN (1936) [Regularities of mass flying of the adult Loxostege sticticalis L., and the problem of prognosis of their flight migrations]. Bulletin Plant Protection, Leningrad. Series 1, Entomology, no. 17 (see Rev Appl Entomol (A) 24:816-817)

Pedgley DE (1982) Windborne pests and diseases: meteorology of airborne organisms. Ellis Horwood, Chichester, UK

Pedgley DE (1993) Managing migratory insects pests - a review. Int J Pest Manag 39:3-12

Pedgley DE, Reynolds DR, Riley JR, Tucker MR (1982) Flying insects reveal small-scale wind systems. Weather 37:295-306 
Pedgley DE, Reynolds DR, Tatchell GM (1995) Long-range insect migration in relation to climate and weather: Africa and Europe. In: Drake VA, Gatehouse AG (eds) Insect Migration: Tracking Resources through Space and Time. Cambridge University Press, Cambridge, UK, pp. 3-29

Rainey RC (1974) Biometeorology and insect flight: some aspects of energy exchange. Ann Rev Ent 19:407-439

Reid DG, Wardhaugh KG, Roffey J (1979) Radar studies of insect flight at Benalla, Victoria, in February 1974. CSIRO Australia, Division of Entomology Technical Paper no. 16

Reynolds DR, Chapman JW, Edwards AS, Smith AD, Wood CR, Barlow JF, Woiwod IP (2005) Radar studies of the vertical distribution of insects migrating over southern Britain: the influence of temperature inversions on nocturnal layer concentrations. Bull Ent Res $95: 259-274$

Reynolds DR, Riley JR (1997) The flight behaviour and migration of insect pests: radar studies in developing countries. NRI Bulletin no. 71. Natural Resources Institute, Chatham, UK Riley JR (1989) Orientation by high-flying insects at night: observations and theories. In: Orientation and Navigation - Birds, Humans and other animals. Conference of the Royal Institute of Navigation, Cardiff, 6-8 April 1989. The Royal Institute of Navigation, London

Riley JR, Cheng XN, Zhang XX, Reynolds DR, Xu GM, Smith AD, Cheng JY, Bao AD, Zhai BP (1991) The long-distance migration of Nilaparvata lugens (Stål) (Delphacidae) in China: radar observations of mass return flight in the autumn. Ecol Ent 16:471-489

Riley JR, Reynolds DR (1979) Radar-based studies of the migratory flight of grasshoppers in the middle Niger area of Mali. Proc Roy Soc Lond B 204:67-82

Riley JR, Reynolds DR (1986) Orientation at night by high-flying insects. In: Danthanarayana, W (ed) Insect Flight: Dispersal and Migration, Springer-Verlag, Berlin, Heidelberg, pp. $71-87$ 
Riley JR, Reynolds DR, Farmery MJ (1983) Observations of the flight behaviour of the armyworm moth, Spodoptera exempta, at an emergence site using radar and infra-red optical techniques. Ecol Ent 8:395-418

Riley JR, Reynolds DR, Farrow RA (1987) The migration of Nilaparvata lugens (Stål) (Delphacidae) and other Hemiptera associated with rice during the dry season in the Philippines: a study using radar, visual observations, aerial netting and ground trapping. Bull Ent Res 77:145-169

Schaefer GW (1976) Radar observations of insect flight. Symp R Ento Soc Lond 7:157-197

Smith AD, Reynolds DR, Riley JR (2000) The use of vertical-looking radar to continuously monitor the insect fauna flying at altitude over southern England. Bull Ent Res 90:265-277

Smith AD, Riley JR, Gregory RD (1993) A method for routine monitoring of the aerial migration of insects by using a vertical-looking radar. Phil Trans Royal Soc Lond B 340:393-404

Taylor LR (1974) Insect migration, flight periodicity and the boundary layer. J Anim Ecol $43: 225-238$

Taylor LR, Carter CI (1961) The analysis of numbers and distribution in an aerial population of macrolepidoptera. Trans Roy Ent Soc Lond 113:369-386

Taylor LR, French RA, Macaulay EDM (1973) Low-altitude migration and diurnal flight periodicity; the importance of Plusia gamma L. (Lepidoptera: Plusidae). J Anim Ecol $42: 751-760$

Thorpe AJ, Guymer TH (1977) The nocturnal jet. Quart J R Meteorol Soc 103:633-653

Vaughn CR (1985) Birds and insects as radar targets: a review. Proc IEEE 73:205-227

Wilson DR, Ballard SP (1999) A microphysically based precipitation scheme for the UK Meteorological Office Unified Model. Quart J R Meteorol Soc 125:1607-1636 
Woiwod IP, Harrington R (1994) Flying in the face of change - the Rothamsted Insect Survey. In: Leigh RA, Johnson AE (eds) Long-term experiments in agricultural and ecological sciences. CAB International, Wallingford, UK, pp. 321-342

Wolf WW, Westbrook JK, Raulston J, Pair SD, Hobbs SE (1990) Recent airborne radar observations of migrant pests in the United States. Phil Trans Roy Soc B 328:619-630

Wolf WW, Westbrook JK, Sparks AN (1986) Relationships between radar entomological measurements and atmospheric structure in south Texas during March and April 1982. In: Sparks AN (ed) Long-range migration of moths of agronomic importance to the United States and Canada: Specific examples of the occurrence and synoptic weather patterns conducive to migration. U.S. Department of Agriculture, Agricultural Research Service ARS-43, pp. 84-97 


\section{Legends}

Fig. 1 Evolution of insect aerial density (numbers per $10^{7} \mathrm{~m}^{3}$ ) with altitude and time for the night of 22-23 August 2000 at Malvern. The insect layer formed at 20:00UTC at $250 \mathrm{~m}$ and (rising in altitude) persisted until 01:00UTC. Only insects with mass $10 \mathrm{mg}$ or greater have been included. Sunset was at 19:18, and the end of dusk is represented by a marker on the time axis at 19:48.

Fig. 2 Back trajectories calculated for an air parcel located near the insect layer height (300 $\mathrm{m}$ agl) and crossing the Malvern site at the time of layer termination. The trajectories show the presumed origin of the air parcel at dusk (5 hours previously). (A) 22-23 August 2000, (B) 14-15 August 2003, (C) 23-24 August 2003.

Fig. 3 Evolution of temperature $\left({ }^{\circ} \mathrm{C}\right)$ with altitude and time for the night of 22-23 August 2000 at Malvern. The magenta coloured line marks the top of the temperature inversion (altitude of warmest air). Superimposed are the insect aerial density contours from Fig. 1 for $25(--)$ and $50(-)$ insects per $10^{7} \mathrm{~m}^{3}$, which indicate the development of the insect layer.

Fig. 4 Evolution of wind speed $\left(\mathrm{m} \mathrm{s}^{-1}\right)$ with altitude and time for the night of 22-23 August 2000 at Malvern. Superimposed are the insect aerial density contours from Fig.1 for 25 (--) and $50(-)$ insects per $10^{7} \mathrm{~m}^{3}$, which indicate the development of the insect layer. 
Fig. 5 Evolution of net insect displacement speed (ground speed) $\left(\mathrm{m} \mathrm{s}^{-1}\right)$ with altitude and time, on the night of 22-23 August 2000 at Malvern. Sunset was at 19:36, and the end of dusk is represented by a marker on the time axis at 20:06.

Fig. 6 Equi-areal plot showing distribution of body alignments for insects flying in the layer in range-gates 3-5 at 290-480 m above ground from 21:00-01:00 UTC on 22-23 August 2000. $14.9 \%$ of the targets were aligned along $60-240^{\circ}$ axis.

Fig. 7 Mass distributions of insects forming nocturnal layers at Malvern. (A) 20:00-01:00 UTC on 22-23 August 2000 (B) 21:00-01:00 on 14-15 August 2003 and (C) 21:00-01:00 on 23-24 August 2003. Only insects of mass $10 \mathrm{mg}$ or greater have been included.

Fig. 8 Evolution of temperature $\left({ }^{\circ} \mathrm{C}\right)$ with altitude and time, on the night of 14-15 August 2003 at Malvern. Superimposed are the insect aerial density contours of $25(---)$ and $50(-)$ insects per $10^{7} \mathrm{~m}^{3}$ as detected by the Malvern radar, which indicate the development of the insect layer. Sunset was at 19:36, and the end of dusk is represented by a marker on the time axis at 20:06.

Fig. 9 Evolution of wind speed $\left(\mathrm{m} \mathrm{s}^{-1}\right)$ with altitude and time, on the night of 14-15 August 2003 at Malvern. Superimposed are the insect aerial density contours of $25(---)$ and $50(-)$ insects per $10^{7} \mathrm{~m}^{3}$, which indicate the development of the insect layer.

Fig. 10 Evolution of temperature $\left({ }^{\circ} \mathrm{C}\right)$ with altitude and time, on the night of 23-24 August 2003 at Malvern. Superimposed are the insect aerial density contours of 25 (---) and 50 (-) 
insects per $10^{7} \mathrm{~m}^{3}$, which indicate the development of the insect layer. Sunset was at 19:18, and the end of dusk is represented by a marker on the time axis at 19:48.

Fig. 11 Evolution of wind speed $\left(\mathrm{m} \mathrm{s}^{-1}\right)$ with altitude and time, on the night of 23-24 August 2003 at Malvern. Superimposed are the insect aerial density contours of 25 (---) and 50 (一) insects per $10^{7} \mathrm{~m}^{3}$, which indicate the development of the insect layer. 

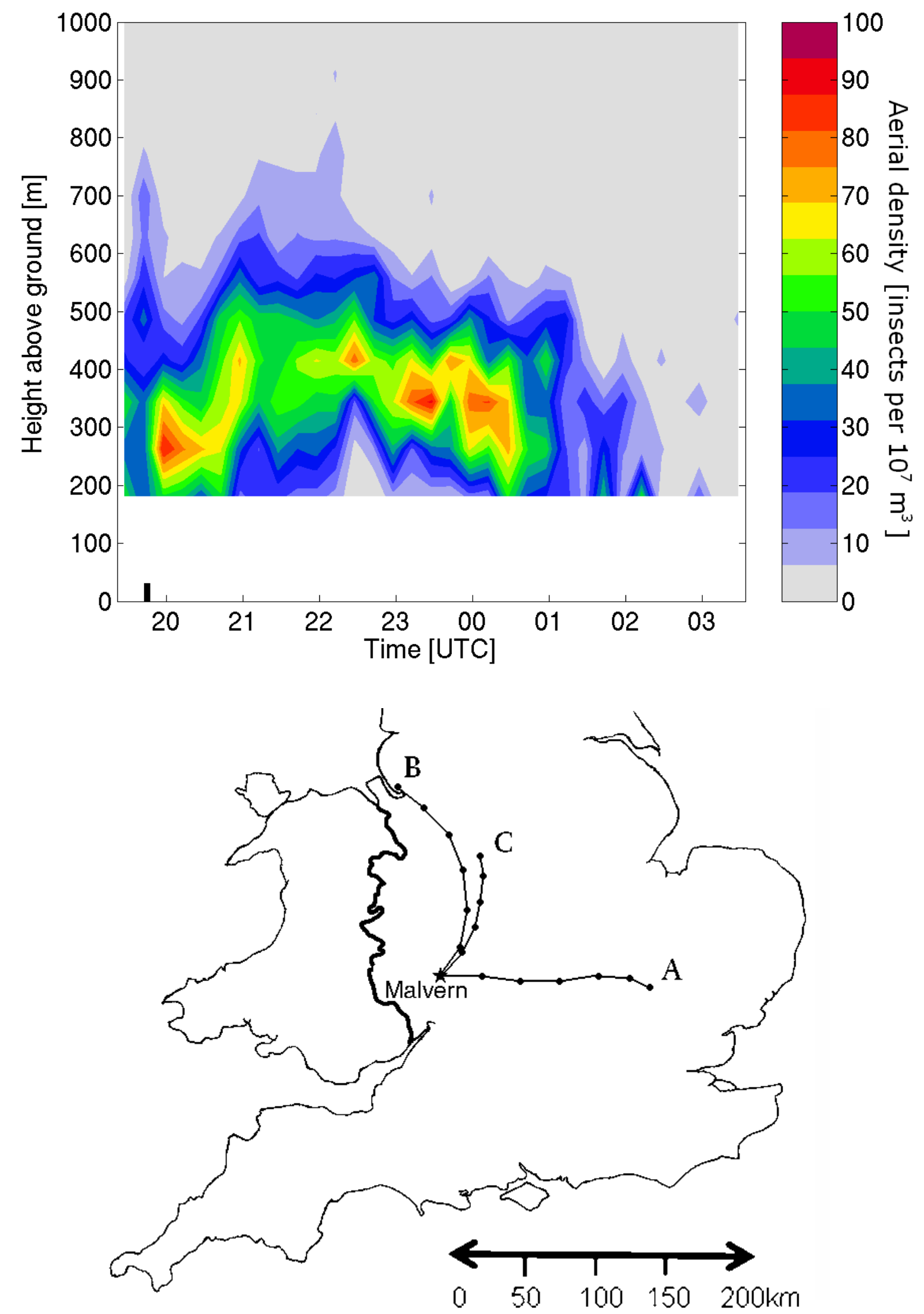

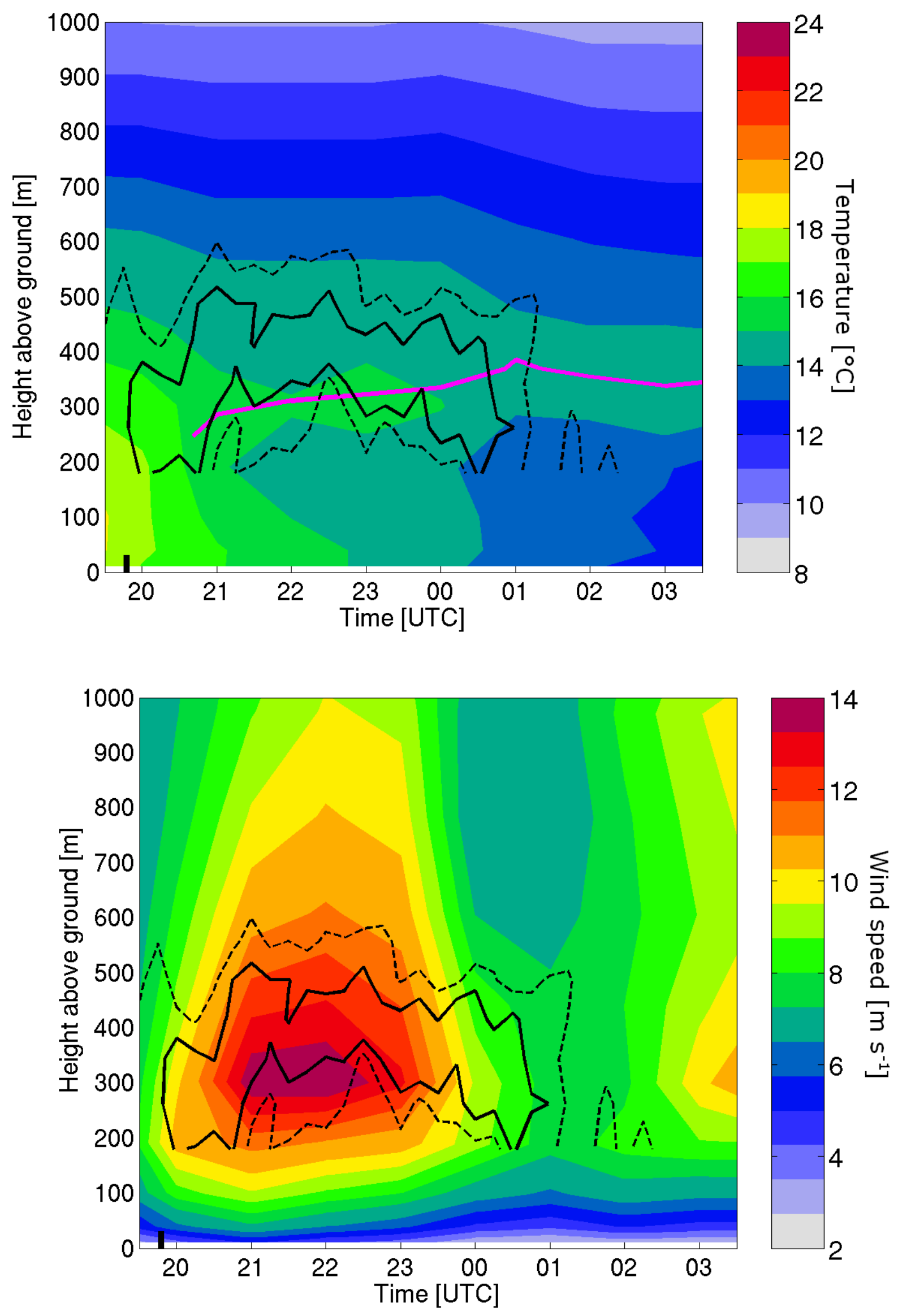


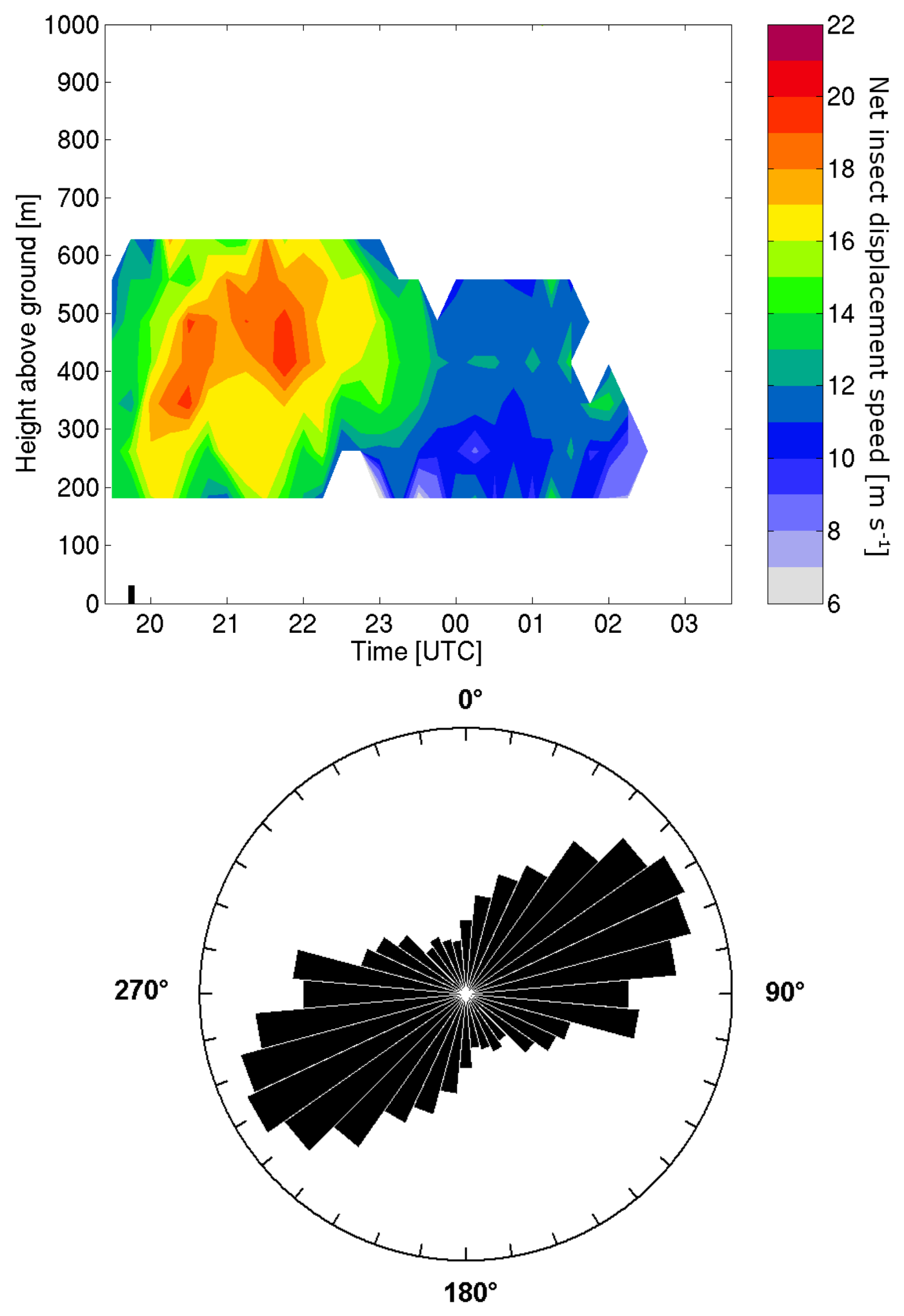




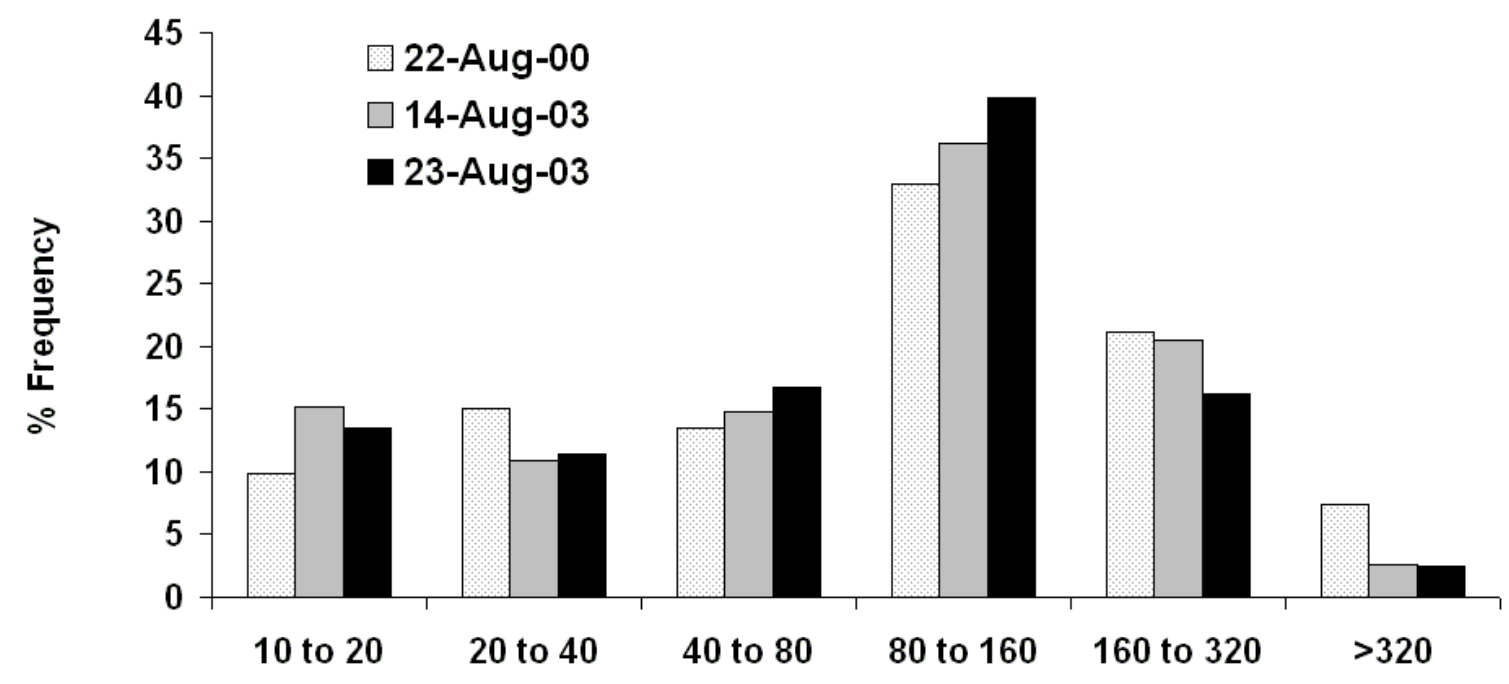

Mass range (mg)

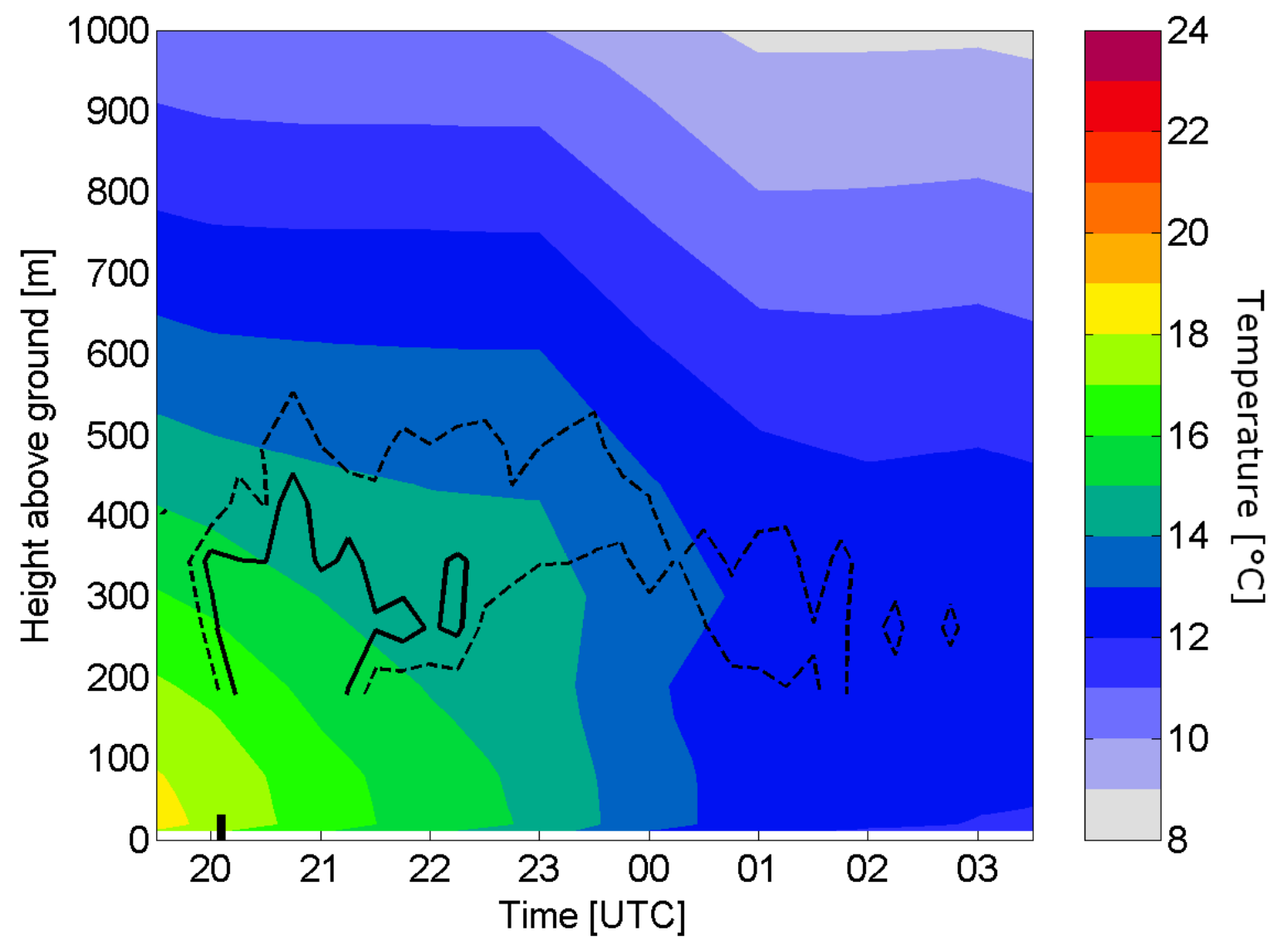



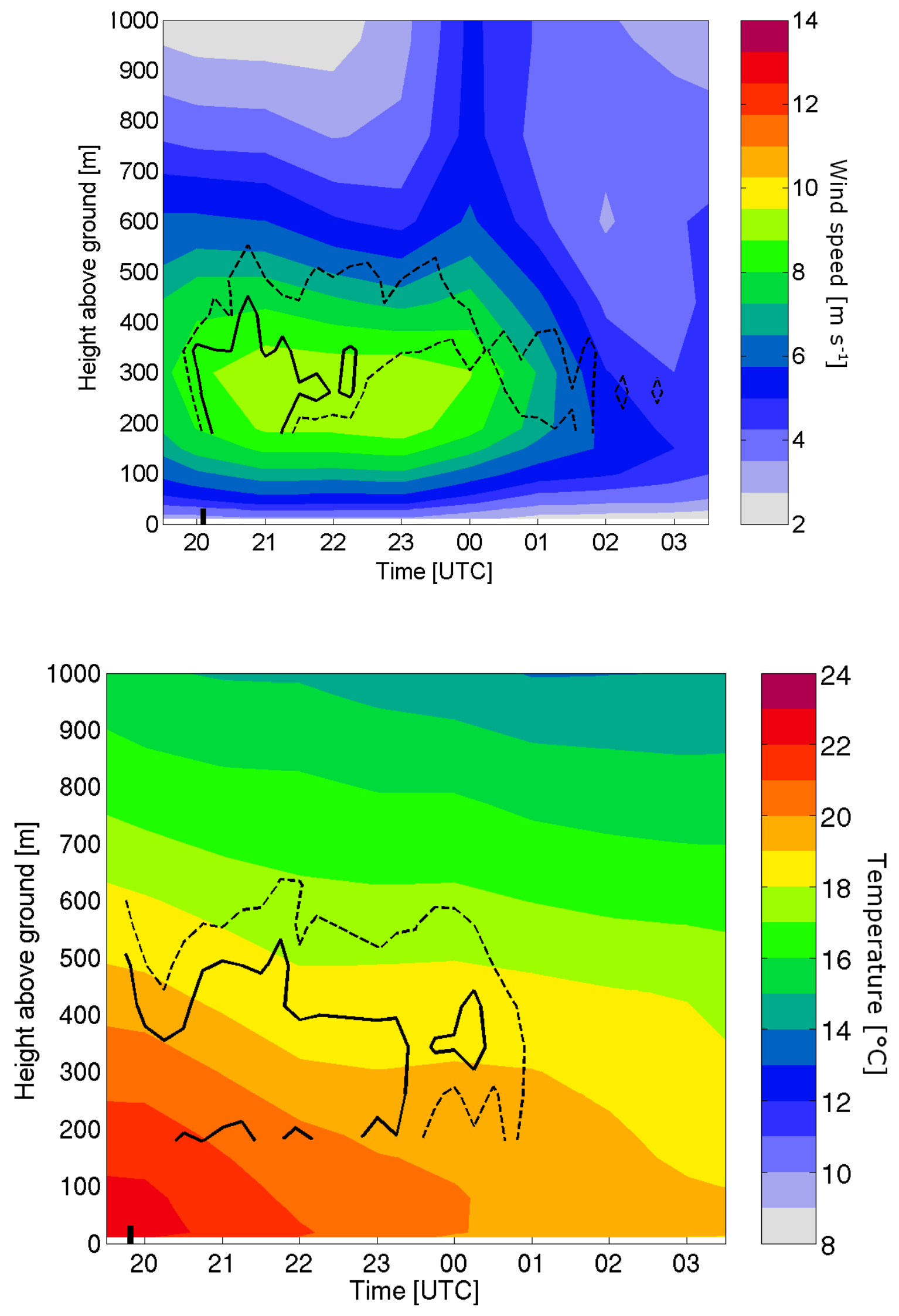


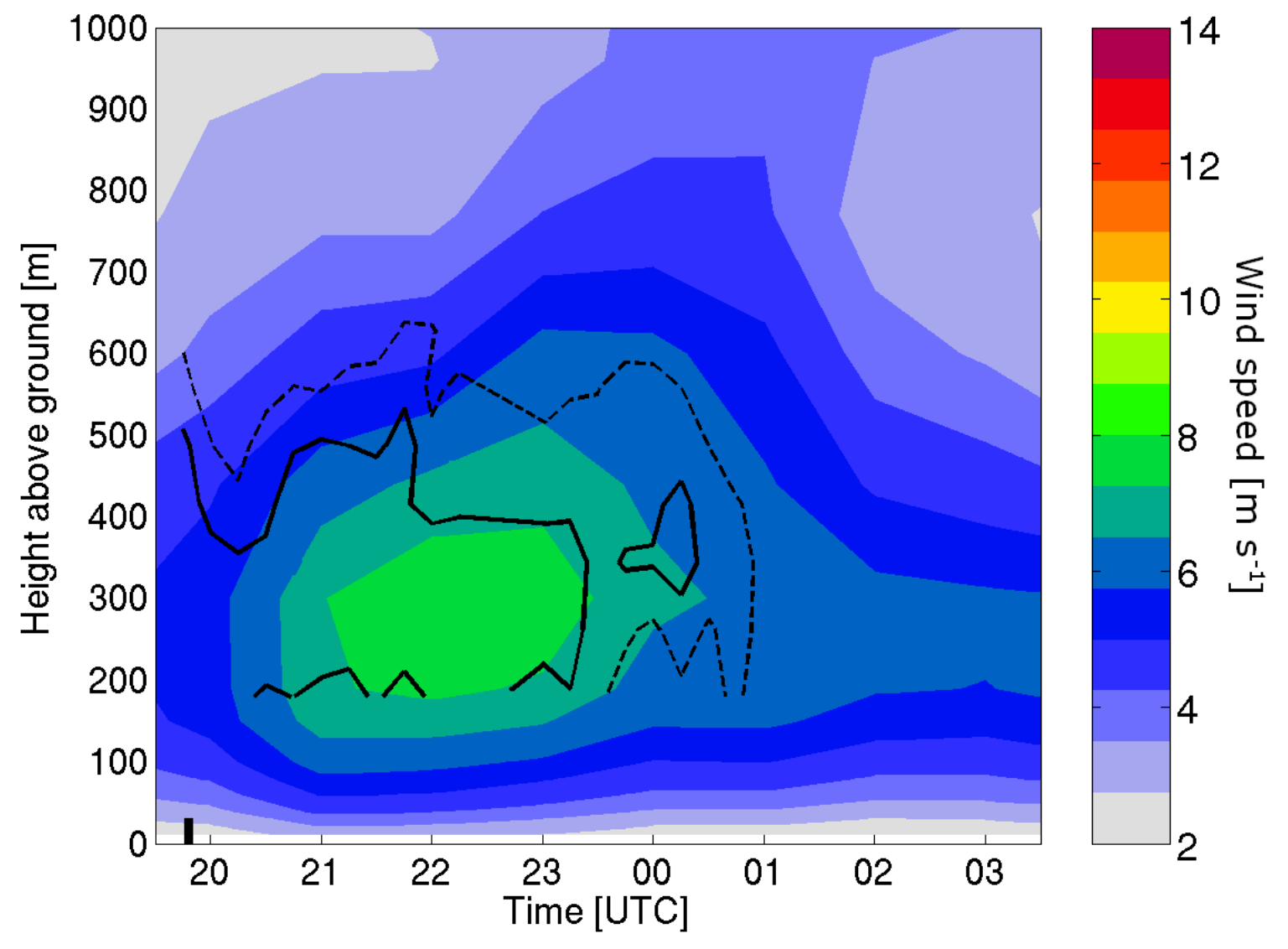

